\title{
Biliary Cast Syndrome Following Liver Transplantation: A Challenging Case
}

\author{
Mahek Shah ${ }^{\mathrm{a}, \mathrm{c}}$, Ritika Puri ${ }^{\mathrm{b}}$, Obiora Maludum ${ }^{\mathrm{b}}$, Soumya Patnaik ${ }^{\mathrm{b}}$, \\ Marvin $\mathrm{Lu}^{\mathrm{b}}$
}

\begin{abstract}
Biliary cast syndrome (BCS) complicates up to one in six patients post-orthotopic liver transplant (OLT). Management of BCS is challenging with limited success using endoscopic retrograde cholangiopancreatography (ERCP) or open exploration to clear the casts with some patients requiring re-transplantation. We present a case of BCS in a patient who suffered from vascular complications at the time of OLT rendering him a non-candidate for repeat liver transplantation in addition to increasing risk for ischemic insult and biliary strictures, and the challenges faced in his care.
\end{abstract}

Keywords: Biliary cast; Cirrhosis; Sludge; Bilioma; Duct dilation; Liver transplant

\section{Introduction}

Biliary cast syndrome (BCS) is a complication that affects $5-18 \%$ of orthotopic liver transplant (OLT) recipients $[1,2]$. $\mathrm{BCS}$ is characterized by the presence of retained lithogenic material within the bile ducts causing inflammation of the biliary system and hepatocyte damage leading to liver dysfunction [3]. Biliary cast formation may contribute to exudative inflammation of bile duct epithelium in addition to other factors that contribute to biliary epithelial injury [4-6]. There has been debate over the pathogenesis for development of BCS with theories involving biliary obstruction or infection, immune mediated rejection, and placement of biliary drainage tubes as possible mechanisms that lead to BCS $[7,8]$. Some studies have demonstrated that ischemic factors and biliary strictures may contribute to the development of BCS [9]. Management

Manuscript accepted for publication March 24, 2016

aDepartment of Cardiology, Lehigh Valley Health Network, Allentown, PA, USA

bepartment of Medicine, Einstein Medical Center, Philadelphia, PA, USA

${ }^{\mathrm{c} C}$ Corresponding Author: Mahek Shah, Lehigh Valley Health Network, 1250S

Cedar Crest Blvd, Suite 300, Allentown, PA 18103, USA.

Email: mahek.shah@1vhn.org

doi: http://dx.doi.org/10.14740/jmc2467w of BCS is challenging, with varying success reported using endoscopic retrograde cholangiopancreatography (ERCP) and open exploration to clear the casts $[2,8,10]$. In some refractory cases, the only effective treatment is re-transplantation.

We present a patient diagnosed with intractable epigastric pain due to BCS and the challenges faced during management of the disease.

\section{Case Report}

We report the case of a 58-year-old male with history of an OLT 13 months ago for hepatitis $\mathrm{C}$ virus (HCV) cirrhosis complicated by hepatocellular carcinoma who presented to the hospital with progressive epigastric abdominal pain, nausea and vomiting. During the OLT, he had received an aortic jump bypass graft due to stenosis of his native hepatic arteries. His post-transplant course was complicated by recurrent infections, para-aortic hematoma, and multiple hepatic biliomas.

During his current hospital stay, the patient was found to have elevated liver function tests, including alkaline phosphatase levels $>1,400 \mathrm{IU} / \mathrm{L}$ and a direct bilirubin of $1.6 \mathrm{mg} /$ dL. A right upper quadrant ultrasound, CT scan of the abdomen and confirmatory cholangiogram showed worsening in-

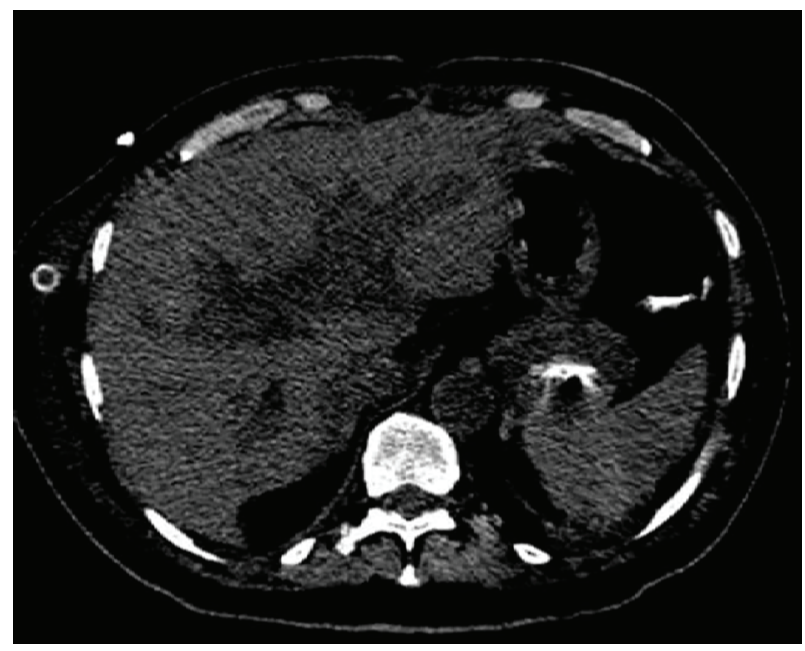

Figure 1. Computed tomographic scan of the abdomen showing dilation of the intrahepatic biliary ductal system. 


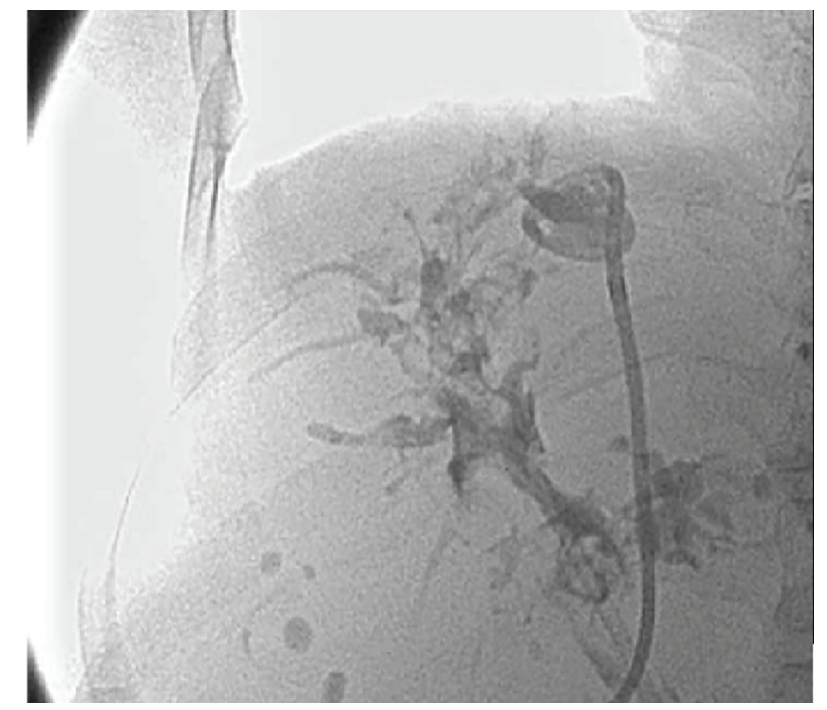

Figure 2. Percutaneous cholangiogram demonstrating multiple biliary strictures, dilations and filling defects seen within the liver as seen in our patient.

trahepatic biliary dilatation and extensive biliary sludge with some narrowing of the extrahepatic bile ducts (Figs. 1-3). The patient underwent an ERCP with sphincterotomy, biliary irrigation and placement of a biliary stent to facilitate bile flow.

$\mathrm{He}$ was diagnosed with $\mathrm{BCS}$ and required multiple repeat
ERCP procedures to remove bile casts for symptomatic relief. He was deemed a poor candidate for re-transplantation due to his stenotic vasculature. Goals of care were addressed and management was focused on symptom control due to the refractory nature of his disease.

\section{Discussion}

Biliary complications occur in 6-34\% of all liver transplant patients. Biliary sludge and stones are most commonly seen [11]. $\mathrm{BCS}$ is associated high rates of morbidity, mortality, and rejection of the graft [4]. It usually presents within $2-12$ months from the transplant [9]. BCS after OLT is difficult to treat and usually results in re-transplantation or death.

Many BCS patients develop jaundice, dark urine, fevers and pruritis. Serum levels of alanine aminotransferase (ALT), $\gamma$-glutamyl transpeptidase (GGT), alkaline phosphatase (ALP), and total bilirubin may be normal to increased in most patients with BCS. The clinical presentation may vary from asymptomatic to a varying severity of the symptoms mentioned above. Despite a lack of clinical symptoms or laboratory index changes, intrahepatic biliary tract filling defects and bile casts may be seen in the patients on ERCP or other imaging techniques [12].

Our patient was at a high risk for ischemic complications due to the stenotic nature of his native hepatic vessels requiring an aortic jump graft. The association between hepatic artery

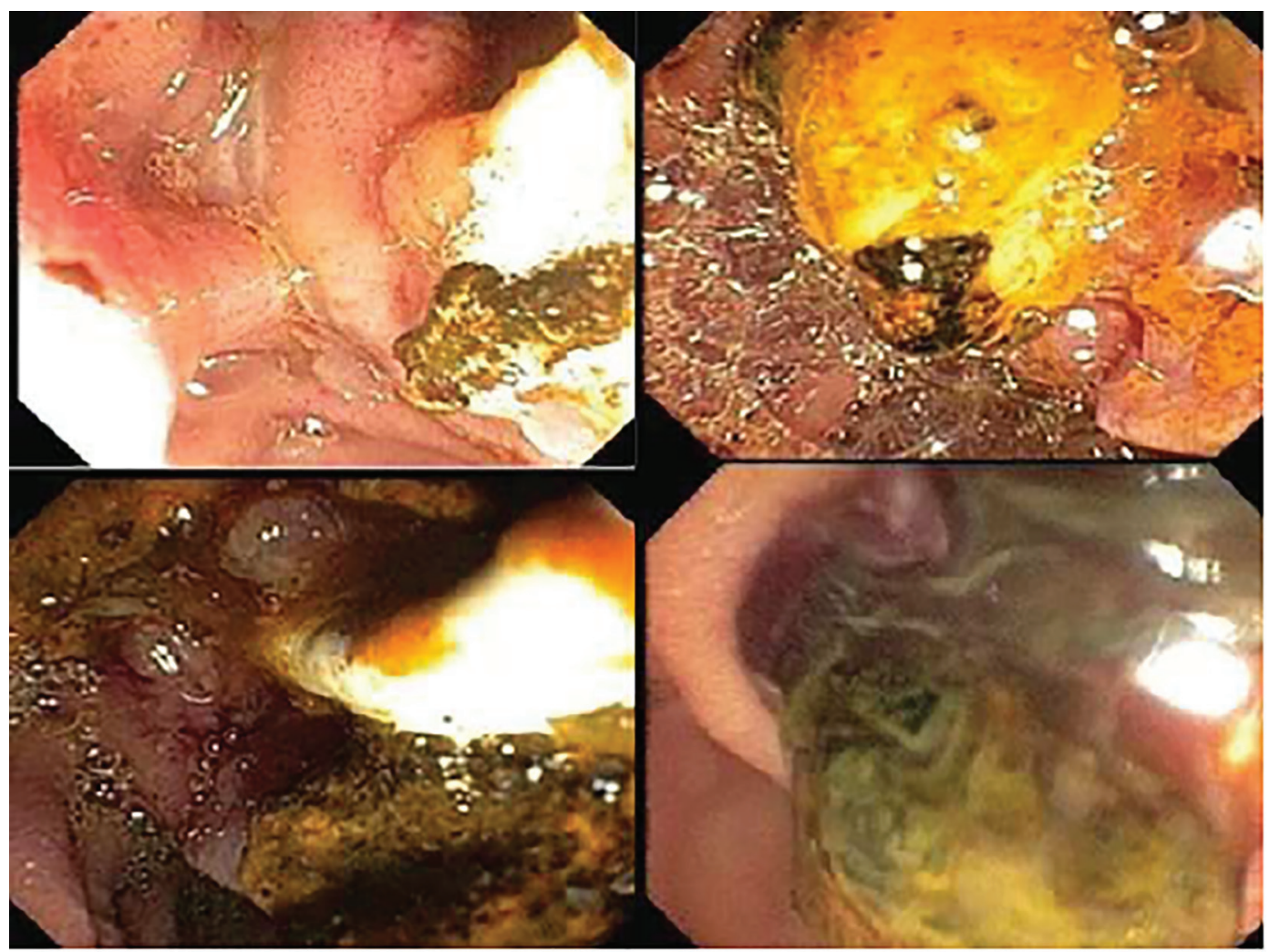

Figure 3. Images obtained during endoscopic retrograde cholangiopancreatography with presence of extensive biliary sludging and casts. 
thrombosis and stenosis and biliary ischemia is controversial but recent literature does suggest a possible link between the two $[9,12]$. Unfortunately, the unfavorable anatomy of his hepatic vessels made him a non-candidate for re-transplantation.

Biliary complications have been reported to be successfully treated by endoscopic cholangiography and in some cases by percutaneous techniques along with extraction, irrigation of the bile ducts, and the use of stents when indicated. However, multiple procedures are often required as in our case due to recurrent formation of casts. Surgical intervention has been recommended for removal of the casts especially in cases where there may be extensive involvement of intra and extra-hepatic ducts. Most of the patients who continue to have symptoms despite repeated interventions need to be considered for retransplantation keeping in mind the high morbidity and mortality associated with this disease $[10,11,13]$. In the case of our patient, he was not a candidate for re-transplantation. After an extensive family discussion, it was thought appropriate to prioritize palliation of symptoms due to a lack of treatment options and the patient passed away on comfort measures as his condition continued to decline.

Studies have also documented a possible link between $\mathrm{BCS}$ and prolonged warm ischemic time, non-heart-beating donor grafts and hepatic artery stenosis $[12,14]$.

Given the negative impact of BCS on liver transplant outcomes and the limited number of controlled trials on this subject, further large-scale studies are needed.

\section{Conflict of Interest}

No potential conflict of interest relevant to this article was reported by all authors of the study.

\section{References}

1. Barton P, Maier A, Steininger R, Muhlbacher F, Lechner G. Biliary sludge after liver transplantation: 1. Imaging findings and efficacy of various imaging procedures. AJR Am J Roentgenol. 1995;164(4):859-864.

2. Canete JJ, Aidlen JT, Uknis ME, Cicalese L. Images of interest. Hepatobiliary and pancreatic: biliary cast syndrome. J Gastroenterol Hepatol. 2005;20(5):791.

3. Voigtlander T, Negm AA, Strassburg CP, Lehner F, Manns MP, Lankisch TO. Biliary cast syndrome post- liver transplantation: risk factors and outcome. Liver Int. 2013;33(8):1287-1292.

4. Waldram R, Williams R, Calne RY. Bile composition and bile cast formation after transplantation of the liver in man. Transplantation. 1975;19(5):382-387.

5. Zhu XD, Shen ZY, Zeng R, et al. Experience in treatment of biliary cast syndrome in 103 patients after liver transplantation. Zhonghua Gandan Waike Zazhi. 2007;174178.

6. Heidenhain C, Pratschke J, Puhl G, Neumann U, Pascher A, Veltzke-Schlieker W, Neuhaus P. Incidence of and risk factors for ischemic-type biliary lesions following orthotopic liver transplantation. Transpl Int. 2010;23(1):14-22.

7. Starzl TE, Putnam CW, Hansbrough JF, Porter KA, Reid HA. Biliary complications after liver transplantation: with special reference to the biliary cast syndrome and techniques of secondary duct repair. Surgery. 1977;81(2):212221.

8. Chan SC, Lo CM, Liu CL, Fan ST. Resurgence of biliary cast syndrome. Liver Transpl. 2005;11(2):242-243.

9. Shah JN, Haigh WG, Lee SP, Lucey MR, Brensinger CM, Kochman ML, Long WB, et al. Biliary casts after orthotopic liver transplantation: clinical factors, treatment, biochemical analysis. Am J Gastroenterol. 2003;98(8):18611867.

10. Pfau PR, Kochman ML, Lewis JD, Long WB, Lucey MR, Olthoff K, Shaked A, et al. Endoscopic management of postoperative biliary complications in orthotopic liver transplantation. Gastrointest Endosc. 2000;52(1):55-63.

11. Bak SH, Choi HS, Yang SY, Jun DW, Han SH, Lee HL, Lee OY, et al. [Obstructive jaundice due to biliary cast syndrome followed by orthotopic liver transplantation]. Korean J Gastroenterol. 2006;48(2):119-123.

12. Zhu XD, Shen ZY, Chen XG, Zang YJ. Pathotyping and clinical manifestations of biliary cast syndrome in patients after an orthotopic liver transplant. Exp Clin Transplant. 2013;11(2):142-149.

13. Barton P, Steininger R, Maier A, Muhlbacher F, Lechner G. Biliary sludge after liver transplantation: 2. Treatment with interventional techniques versus surgery and/or oral chemolysis. AJR Am J Roentgenol. 1995;164(4):865869.

14. Abt P, Crawford M, Desai N, Markmann J, Olthoff K, Shaked A. Liver transplantation from controlled nonheart-beating donors: an increased incidence of biliary complications. Transplantation. 2003;75(10):1659-1663. 